\title{
Cyclic Fatigue Resistance of New Endodontic Files in Reciprocal vs. Rotational Motion.
}

\author{
Makdad Chakmakchi \\ B.D.S, Ph.D. Assistant Professor. University of Mosul, College of Dentistry \\ Ashraf Salim Alchalabi \\ B.D.S, M.Sc. Ph.D. Student. Department of Conservative Dentistry. College of Dentistry
}

\begin{abstract}
Objectives: To evaluate the flexural fatigue resistance of WaveOne Primary and Protaper NEXT X2 NiTi files used in reciprocating and rotation motions.

Materials and methods: A 20 files, $25 \mathrm{~mm}$ long for use in reciprocating [Group 1: WaveOne Primary, $\mathrm{n}=10$ ] and continuous rotation [Group 2: Protaper NEXT X2, n=10] were selected. All instruments were operated in a static model for cyclic fatigue testing which was conducted in a device that allowed for a reproducible simulation of an instrument confined in a curved canal. The instruments were activated by a torque-controlled motor [X-smart plus, Dentspy Maillefer] using the preset program WaveOne ALL for the WaveOne instruments and the preset program for the Ppotaper NEXT X2 instruments. All instruments were rotated until fracture occurred. The number of cycles to failure [NCF] for each instrument was calculated. The length of the fractured file tip was measured. NCF data were statistically analyzed by Student $t$-test.

Results: The statistical analysis revealed a statistically significant differences $[p<0.001]$ between two groups. WaveOne primary instruments were associated with a significantly greater NCF.

Conclusions: The test results showed significantly increased cyclic fatigue resistance of the file with reciprocal motions compared to continuous rotation. No differences were found between the lengths of the fractured segment.
\end{abstract}

KEYWORDS

number of cycles to failure, nickel-titanium file, reciprocation, fatigue resistance, endodontic files.

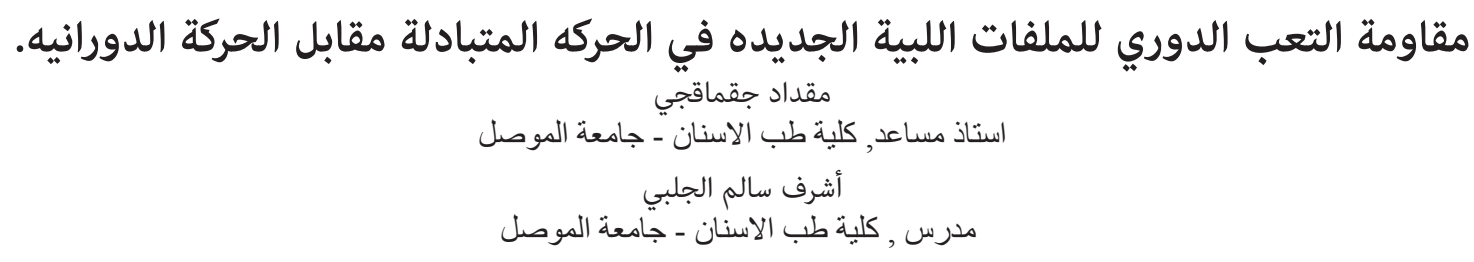

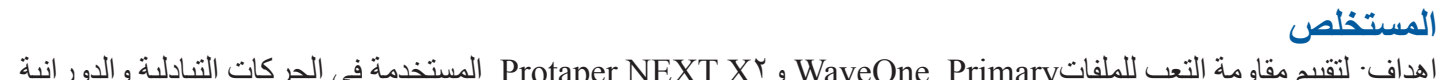

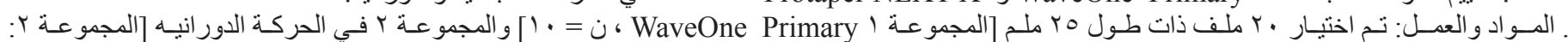

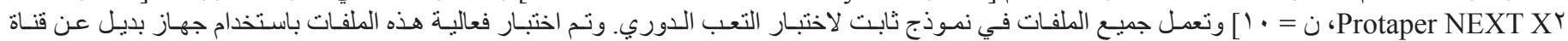

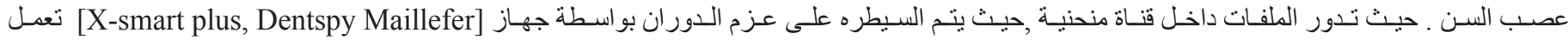

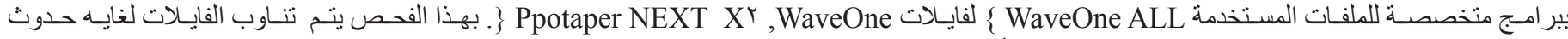

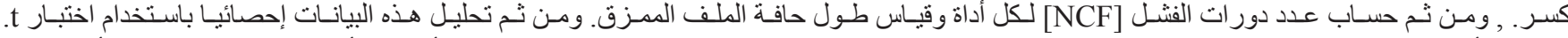

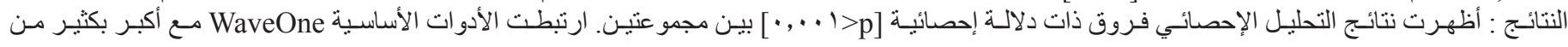
[NCF]

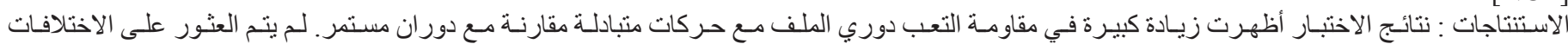

\section{INTRODUCTION}

The introduction of rotary nickel-titanium [NiTi] endodontic instruments into clinical practice has improved the efficacy of endodontic treatment in terms of procedural time, accuracy, and risk reduction (1-3). However, despite these advantages, unexpected instrument fracture is not uncommon ${ }^{(1)}$. Sattapan et al identified two modes of fracture for arotary NiTi instruments: torsional failure and cyclic fatigue ${ }^{(4)}$. The torsional failure occurs when the tip or any part of the instrument is locked into the canal, while rotary motion continues. The fracture caused by fatigue failure is caused by flexure. The rotating instrument in a root canal curvature, is subjected to tension/ compression cycles at the point of maximum flexure, until fracture occurs ${ }^{(5,6)}$. During rotation, half of the instrument shaft is in tension (outer curved part), whereas the rest is in compression (concave part). This repeated tension-compression cycle loading, increases cyclic fatigue of the instrument over time and has been identified as an important factor in instrument fracture ${ }^{(5,6)}$.

Cyclic fatigue resistance of a file system is usually tested by counting the number of rotations of the instrument in an artificial root canal until fracture (7). The clinical concern is the fact that cyclic fatigue occurs with no visible signs of plastic deformation. Therefore, clinicians should be aware of the most influential factors that contribute to this type of failure, to prevent instrument fracture ${ }^{(8)}$. 
To improve the fracture resistance of rotary nickel titanium files, manufacturers have introduced new alloys and developed new manufacturing processes ${ }^{(8)}$. M-wire is a new NiTi alloy prepared by a special thermal process incorporating three crystalline phases (deformed and micro-twinned marten site, R-phase and austenite). This structure is believed to offer increased flexibility and resistance to cyclic fatigue in comparison with conventional nickel titanium alloys (9)

In addition, the use of reciprocating motion has been shown to extend the lifespan of a NiTi instrument in comparison with continuous rotation ${ }^{(10,11)}$.

Recently, a new brand of NiTi instruments were introduced to the market based on the above developments: WaveOne Primary (Dentsply Maillefer, Ballaigues, Switzerland), a $4^{\text {th }}$ generation reciprocal file, has been claimed to reduce torsional stress by periodically reversing the file and therefore increasing the instrument life span ${ }^{(10,12)}$. Protaper NEXT X2 [Dentsply Maillefer] a $5^{\text {th }}$ generation rotary file has been launched with an exceptional shaping capacity of severely curved narrow canals, a procedure that was impossible with most NiTi systems commercially available so far.

The reciprocal motion has been shown to offer important advantages for the preparation of curved canals by using a single NiTi file ${ }^{(13-16)}$. The concept of using a single NiTi instrument to prepare the entire root canal is interesting, because the technique is simple, cost effective with a shorter learning curve ${ }^{(17)}$.

Currently, there is limited information about the comparative fatigue performance of these systems. The aim of the present study was to evaluate the flexural fatigue resistance of WaveOne Primary and Protaper NEXT X2 NiTi files used in reciprocating and continuous rotation motions. The null hypothesis was that there is no statistically significant difference between the two systems in the property tested.

\section{MATERIALS AND METHODS}

A total number of 20 files, $25 \mathrm{~mm}$ long for use in reciprocating motion [Group 1: WaveOne Primary, $\mathrm{n}=10$ ] and continuous rotation [Group 2: Protaper NEXT X2, $n=10]$ were selected for this study. The reciprocating instruments had an ISO size 25 at the tip, a taper of .08 at the apical $3 \mathrm{~mm}$ with a decreasing and variable taper up to the end of their working part. The continuous rotation instruments had an ISO size 25 at the tip, a taper of .06 at the apical $3 \mathrm{~mm}$ with a decreasing and variable taper up to the end of their working part and an off-centered, rectangular cross section. All files were free of defects or deformities confirmed under a stereomicroscope [SZR-10; Optika, Bergamo, Italy].

A static model for cyclic fatigue testing was conducted in a custom-made device that allowed for a reproducible simulation of an instrument confined in a curved canal, similar to that described by Plotino et al ${ }^{(17)}$. The artificial canal was manufactured by reproducing the instrument's size and taper, thus providing the instrument with a suitable trajectory that conforms to the parameters of the chosen curvature (Figure 1).

Tempered steel was subjected to computeraided milling to produce an artificial canal of the following dimensions: Total length of $20 \mathrm{~mm}$ starting with a $12 \mathrm{~mm}$ straight part with entrance of $1.3 \mathrm{~mm}$ diameter, $60^{\circ}$ angle of curvature measured according to Schneider ${ }^{(18)}, 5 \mathrm{~mm}$ radius of curvature and length of curved segment, $3 \mathrm{~mm}$ straight part after curvature and $0.6 \mathrm{~mm}$ apical diameter.

The instruments were activated by using a $6: 1$ reduction handpiece powered by a torque-controlled motor [X-smart plus, Dentspy Maillefer] using the preset program WaveOne ALL for the WaveOne instruments and the preset program for the Ppotaper NEXT X2 instruments.

To reduce file friction with artificial canal walls, high-flow synthetic lubricating oil (Super Oil, Singer Co Ltd, Elizabethport, NJ, USA) was applied and the free canal surface was covered with glass to prevent the instruments from slipping out ${ }^{(19)}$.

All instruments were rotated until fracture occurred. The time to fracture was recorded and stopped as soon as a fracture was detected visually and/or audibly using a chronometer (accuracy $\pm 0,01$ s) and registered to the nearest integer second. The length of the fractured tip was also recorded for each instrument.

The number of cycles to failure (NCF) for each instrument was calculated by multiplying the time (in s) to failure by the number of rotations or cycles per second regardless of the rotational direction $(350 \mathrm{rpm}$ for WaveOne all and $300 \mathrm{rpm}$ for PTN X2 according to the manufacturer). The length of the fractured file tip was measured by a digital caliper (Whitworth, China), accurate to $\pm 0.01 \mathrm{~mm}$.

NCF data were statistically analyzed by Student $t$-test with a significance level set at 95\% $(\mathrm{a}=0.05)$ employing IBM SPSS statistics v 19.0.0 software.

\section{RESULTS}

The results of NCF values of the groups tested are 
presented in Table 1. The statistical analysis revealed a statistically significant differences $(p<0.001)$ between two groups. WaveOne primary instruments were associated with a significantly greater NCF.

The mean length of the fractured segment was also recorded in millimeter $(\mathrm{mm})$ to evaluate the correct positioning of the tested instrument inside the canal curvature and whether similar stresses were being induced. No statistically significant difference $(\mathrm{P}<0.01)$ in the mean length of the fractured fragments was evident for the instruments (Table 2).

\section{DISCUSSION}

The aim of this study was to investigate the effect of the type of the file movement on the cyclic fatigue of nickel-titanium instruments of the reciprocal WaveOne and latest rotary PTN X2 files. The results showed a statistically significant difference in the number of cycles to failure (NCF) but not in the fragment lengths between the two products. Therefore the testing hypothesis should be partially rejected for NCF.

File fracture is a major concern during endodontic treatment in curved root canals when using NiTi instruments. The structural characteristics and geometric designs have a critical influence on the fracture susceptibility of NiTi files ${ }^{(20)}$. Movement kinematics (continuous or reciprocating motion) and speed are included among the factors determining the resistance of rotary NiTi instruments to cyclic fracture ${ }^{(10)}$. Previous studies have shown that the fatigue life is affected by the radius and angle of the curvature ${ }^{(21,22)}$.

Several different methods have been used to test cyclic fatigue resistance of NiTi files. According to Yao et al ${ }^{(23)}$, the use of standardized artificial canals in cyclic fatigue experiments minimizes the influence of other variables. In this study, the artificial canal used was manufactured reproducing the instrument's size and taper to standardize the conditions.

Selection of stainless steel to simulate canals was made to minimize wear of canal walls during instrumentation ${ }^{(20,24,25)}$. Also a 5-mm radius was chosen to simulate an abruptly curved canal. Several non-tooth devices ${ }^{(26)}$ were used to investigate in vitro cyclic fatigue resistance in both static and dynamic models. Although dynamic models better simulate clinical brushing or pecking motions ${ }^{(27)}$, the instruments tested are not constrained in a precise trajectory. Moreover, regardless standardization of amplitude and frequency of the axial movements these variables are completely subjective on reproducing the motions manually ${ }^{(28)}$.

In the present study, both instruments were made by the same alloy produced with the same proprietary thermal treatment (M-wire). Thus, even in this case, different results between the instruments should not be related to their metallurgical behavior.

In static models all confounding causes apart from cyclic fatigue are minimized. The results of the present study showed that reciprocal motions (ie, WaveOne Primary) significantly increased the cyclic fatigue resistance of tested file compared with continuous rotation independently from different cross-sections. In agreement with these results, other recent articles reported a higher cyclic fatigue resistance of reciprocating motion than continuous rotation in instruments specifically designed to be used in reciprocal motion as well as in those manufactured for continuous rotation use ${ }^{(12,29)}$. It has been postulated that the increased fatigue resistance occurs because of the release of reaction stresses built up in the material by reversing the rotational direction $(10,11)$.

Although the PTN X2 system had a lower rotations speed $(300 \mathrm{rpm})$ compared to WaveOne Primary system (350 rpm) but the latter showed a higher cyclic fatigue resistance, probably because of the reciprocating movement. The instrument rotates $60^{\circ}$ in each cycle, which means that after 6 cycles, the instrument completes one entire rotation $\left(360^{\circ}\right)^{(30)}$. Thus the instrument is subjected to lower tensile and compressive stress, operating for a longer period of time before failure ${ }^{(28)}$. This research reached similar results as in other studies. A reciprocating motion may decrease the impact of cyclic fatigue on NiTi rotary instrument life compared with rotational motion ${ }^{(10-12)}$.

Also a possible explanation of the different results among the instruments tested in this study can be related to the different cross sectional designs. It has been shown that cross-sectional design has an impact on the stress developed by an instrument under either tension or bending ${ }^{(16,31)}$. Protaper NEXT X2 is made of M-Wire and has an off-centered rectangular cross-section, whereas WaveOne Primary files have a modified convex triangular cross-section at the tip and a convex triangular cross-section in the middle and coronal portion of the instrument.

Although comparisons among the different brands is difficult to make because of their differences in movement, design and cross-sectional areas, the results presented here can be useful for clinical practice.

In conclusion, under these experimental conditions, thereciprocal motions showed significantly increased cyclic fatigue resistance of the file tested 
compared with continuous rotation independently from their cross section. No differences were found between the lengths of the fractured segment in the two tested files.

\section{Acknowledgement}

Sincere appreciation to Professor Dr George Eliades, Director, Department of Biomaterials, University of Athens, School of Dentistry, Greece, for revising the original manuscript.

\section{COMPLIANCE WITH ETHICAL STANDARDS Conflict of interest:}

The author Makdad Chakmakchi confirm that this article content has no conflicts of interest.

The author Ashraf Salim Alchalabi confirm that this article content has no conflict of interest.

\section{Funding:}

The work was supported by the Department of Conservative Dentistry, College of Dentistry, the University of Mosul, Iraq.

\section{Ethical approval:}

This article does not contain any studies with human participants or animals performed by any of the authors.

\section{Informed consent:}

For this type of study, formal consent is not required.

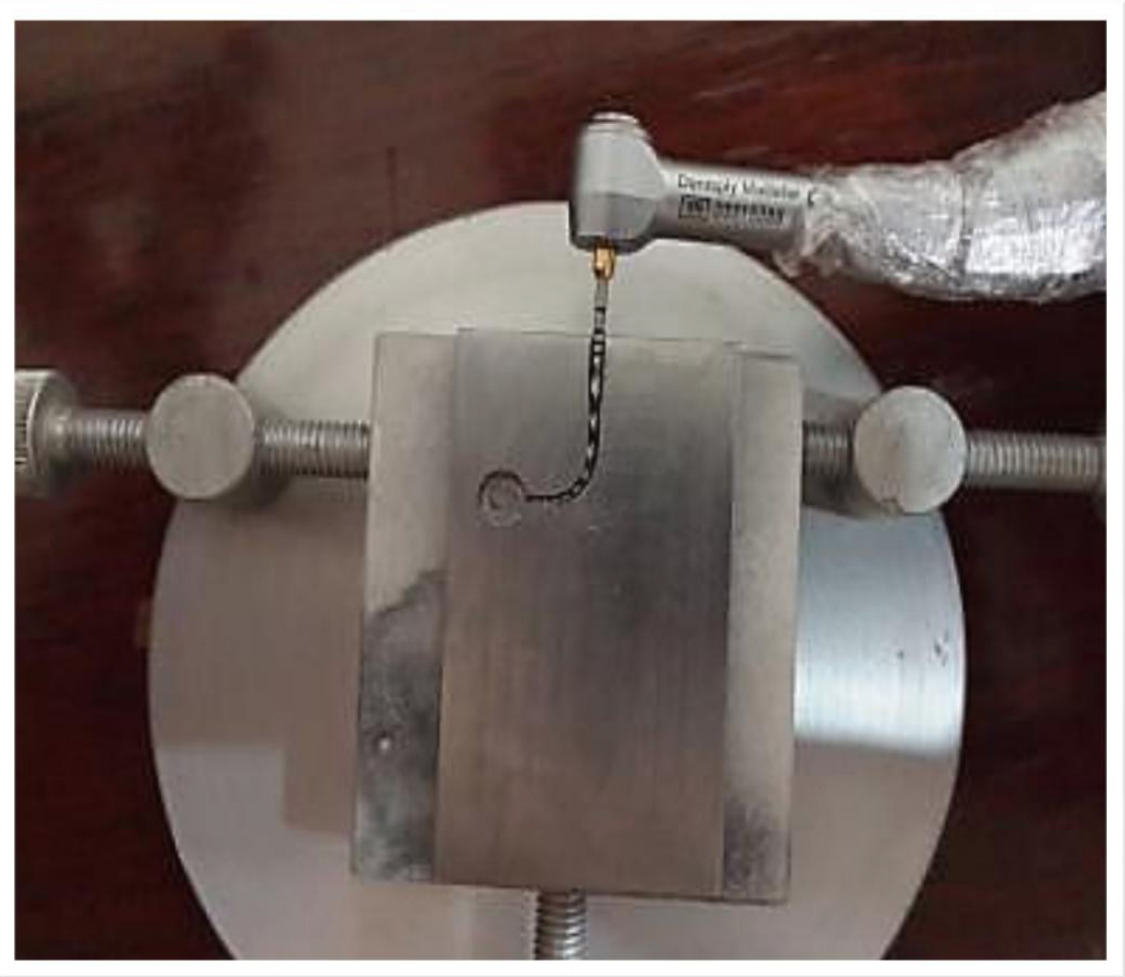

Figure 1. The static model used for cyclic fatigue testing.

Table 1. Results of NCF.

\begin{tabular}{|c|c|c|c|c|c|c|c|}
\hline Groups & $\boldsymbol{N}$ & Minimum & maximum & Mean $\pm S D$ & SE & $t$ & p-value \\
\hline 1.WaveOne Primary & 10 & 310 & 580 & $424 \pm 82$ & 26 & \multirow{2}{*}{6.06} & \multirow{2}{*}{$\mathrm{p}<001 \mathrm{~S}$} \\
\hline 2. Protaper NEXT X2 & 10 & 180 & 300 & $240 \pm 33$ & 10 & & \\
\hline
\end{tabular}

$\mathrm{SD}=$ std.deviation $\quad \mathrm{S}=$ significant

Table 2. Results of fragment lengths [in $\mathrm{mm}]$.

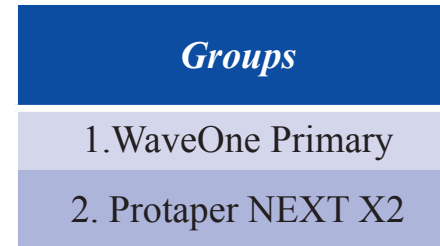

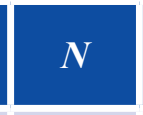

Minimum
mm

\begin{tabular}{|c|}
\hline maximum \\
\hline 5.0 \\
4.97 \\
\hline
\end{tabular}

\begin{tabular}{|c|c|c|}
\hline SE & $\boldsymbol{t}$ & $\boldsymbol{p}$-value \\
\hline 0.12 & & \\
\hline 0.14 & 1.84 & $\mathrm{P}<0.09 \mathrm{NS}$ \\
\hline
\end{tabular}




\section{REFERENCES}

1. Parashos P, Messer HH. Rotary NiTi instrument fracture and its consequences J Endod 2006; 32: 1031-43.

2. Taschieri S, Necchi S, Rosano G, et al. Advantages and limits of nickel-titanium instruments for root canal preparation: a review of the current literature Schweiz Monatsschr Zahnmed 2005; 115 (11): 1000-5.

3. Walia HM, Brantley WA, Gerstein H. An initial investigation of the bending and torsional properties of Nitinol root canal files J Endod 1988; 14: 346-51.

4. Sattapan B, Palamara JE, Messer HH. Torque during canal instrumentation using rotary nickel-titanium files $\mathrm{J}$ Endod 2000; 26: 156-60.

5. Parashos P, Gordon I, Messer HH. Factors influencing defects of rotary nickel titanium endodontic instruments after clinical use J Endod 2004; 30: 722-5.

6. Peters OA. Current challenges and concepts in the preparation of root canal systems: a review J Endod 2004; 30: 559-65.

7. Lee M, Versluis A, Kim B, et al. Correlation between experimental cyclic fatigue resistance and numerical stress analysis for nickel-titanium rotary files J Endod 2011; 37: 1152-7.

8. Saber SE. Factors influencing the fracture of rotary nickeltitanium instruments. ENDO [Lond Engl] 2008; 2: 273 283.

9. Saber SE. The effect of instrument material, taper and degree of root canal curvature on cyclic fatigue of rotary nickeltitanium instruments. ENDO [Lond Engl] 2013; 1: 59-64.

10. De-Deus G, Moreira EJ, Lopes HP, Elias CN. Extended cyclic fatigue life of F2 ProTaper instruments used in reciprocating movement. Int Endod J 2010; 43: 1063-8.

11. You SY, Bae KS, Baek SH, Kum KY, Shon WJ, Lee W. Lifespan of one nickel-titanium rotary file with reciprocating motion in curved root canals J Endod 2010; 36: 1991-4.

12. Varela-Patino $\mathrm{P}$, Ibanez-Parraga A, Rivas-Mundina B, Cantatore G, Otero XL, Martin-Biedma B. Alternating versus continuous rotation: a comparative study of the effect on instrument life J Endod 2010; 36: 157-9.

13. De-Deus G, Brandao MC, Barino B, Di Giorgi K, Fidel RA, Luna AS. Assessment of apically extruded debris produced by the single-file ProTaper F2 technique under reciprocating movement Oral Surg Oral Med Oral Pathol Oral Radiol Endod 2010; 110: 390-4.

14. Franco V, Fabiani C, Taschieri S, Malentacca A, Bortolin M, Del Fabbro M. Investigation on the shaping ability of nickel-titanium files when used with a reciprocating motion J Endod 2011; 37: 1398-1401.

15. Paque F, Zehnder M, De-Deus G. Microtomography based comparison of reciprocating single-file F2 ProTaper technique versus rotary full sequence J Endod 2011; 37: 1394-7.

16. You SY, Kim HC, Bae KS, Baek SH, Kum KY, Lee W. Shaping ability of reciprocating motion in curved root canals: a comparative study with micro-computed tomography J Endod 2011; 37: 1296-300.
17. Plotino G, Grande M, Testarelli L and Gambarini G. Cyclic fatigue of Reciproc and WaveOne reciprocating instruments Int Endod J 2012; 45: 614-8.

18. Schneider SW. A comparison of canal preparations in straight and curved root canals. Oral Surg 1971; 32: 271-5.

19. Pedulla E, Grande NM, Plotino G, Gambarini G, Rapisarda E. Influence of continuous or reciprocating motion on cyclic fatigue resistance of 4 different nickel-titanium rotary instruments J Endod 2013; 39: 258-61.

20. Kim HC, Cheung GS, Lee CJ, Kim BM, Park JK, Kang SI. Comparison of forces generated during root canal shaping and residual stresses of three nickel-titanium rotary files using three-dimensional finite-elements analysis J Endod 2008; 34: 743-7.

21. Grande NM, Plotino G, Pecci R, Bedini R, Malagnino VA, Somma F. Cyclic fatigue resistance and three-dimensional analysis of instruments from two nickel titanium rotary systems Int Endod 2006; J 10: 755-63.

22. Pruett JP, Clement DJ, Carnes DL. Cyclic fatigue testing of nickel-titanium endodontic instruments J Endod 1997; 23: 77-85.

23. Yao JH, Schwartz SA, Beeson TJ. Cyclic fatigue of three types of rotary nickel-titanium files in a dynamic model $\mathrm{J}$ Endod 2006; 32: 55-7.

24. Gambarini G. Cyclic fatigue of Profile rotary instruments after prolonged clinical use Int Endod J 2001; 34: 386-9.

25. Oh SR, Chang SW, Lee Y, Gu Y. A comparison of nickeltitanium rotary instruments manufactured using different methods and cross-sectional areas: ability to resist cyclic fatigue Oral Surg Oral Med Oral Pathol Oral Radiol Endod 2010; 109: 622-8.

26. Plotino G, Grande NM, Cordaro M, et al. A review of cyclic fatigue testing of nickel-titanium rotary instruments $\mathrm{J}$ Endod 2009; 35: 1469-76.

27. Li UM, Lee BS, Shin CT, et al. Cyclic fatigue of endodontic nickel titanium rotary instruments: static and dynamic tests J Endod 2002; 28: 448-51.

28. Wan J, Rasimick BJ, Musikant BL, Deutsch AS. A comparison of cyclic fatigue resistance in reciprocating and rotary nickel-titanium instruments Aust Endod J 2011; 37: 122-7.

29. Gavini G, Caldeira CL, Akisue E, et al. Resistance to flexural fatigue of Reciproc R25 files under continuous rotation and reciprocating movement J Endod 2012; 38: 684-7.

30. Webber J, Machtou P, Pertot W, Kuttler S, Ruddle C, West J. The WaveOne single-file reciprocating system. Roots 2011; 1: 28-33.

31. Cheung GS, Zhang EW, Zheng YF. A numerical method for predicting the bending fatigue life of NiTi and stainless steel root canal instruments Int Endod J 2011; 44: 357-61. 